\title{
Socialized medicine has always been political: COVID-19, science and biopower in India
}

\author{
Aswathy Raveendran ${ }^{1}$. Jesse Bazzul ${ }^{2}$
}

Received: 9 February 2021 / Accepted: 22 October 2021 / Published online: 4 December 2021

(c) The Author(s), under exclusive licence to Springer Nature B.V. 2021

\begin{abstract}
In this article, we discuss the tensions surrounding science, biopower, and citizenship that have been thrown into sharp relief by the COVID 19 pandemic. We situate these tensions in the epistemological and political conflict between science, public health education, and alternative medical systems that has been rekindled by the pandemic in India. To do so, we critically examine media articles and health education documents in the form of illustrated narratives/posters to show how education, science, and biopower are inseparable; and must therefore be considered an important part of any programme of critical justice-oriented science education. We employ a biopolitical framework, drawing largely from the work of Michel Foucault, to expose relevant sociopolitical tensions between tradition and modernity, truth and power, governance and science, which are invoked in times of crisis (such as pandemics) and give shape to fundamentals issue of science and citizenship. This article attempts to add to the conversation begun by Flavia Rezende et al.'s (2021) "South Epistemologies to invent post-pandemic science education", who related the COVID-19 pandemic to the political situation in Brazil emphasizing the necessity to reclaim indigenous ways of being and relating to nature. We draw implications for science education research and praxis that exceed any one pandemic or political crisis.
\end{abstract}

Keywords Pandemic $\cdot$ Biopower $\cdot$ COVID-19 $\cdot$ Power/knowledge $\cdot$ Coloniality $\cdot$ Discourse $\cdot$ Subjectivity

Lead Editor: C. Siry.

This forum is response to Rezende, Ostermann, and Guerra (2021) South epistemologies to invent postpandemic science education. https://doi.org/10.1007/s11422-021-10091-3.

Jesse Bazzul

jesse.bazzul@uregina.ca; jbazzul@gmail.com

Aswathy Raveendran

aswathy@hbcse.tifr.res.in

1 Homi Bhabha Centre for Science Education, Tata Institute of Fundamental Research, V.N. Purav

Marg, Mankhurd, Mumbai, India

2 Department of Education, Maynooth University, Maynooth, Ireland 
While the pandemic gripped China, Europe, and North America in the months of January and February 2020, India woke up to it only in March, after the 'first batch' of Indian tourists returning from abroad tested positive. By the second week of March, the Indian media was abuzz with news on COVID 19, and soon after, residential colleges, universities, and schools shut down, sending their students back home. The 24th of March 2020 marked the beginning of COVID 19 restrictions in India when Prime Minister Narendra Modi announced a 21-day nationwide lockdown, which extended till the 30th of May. The lockdown was imposed immediately after a 14-h voluntary public curfew with the police's active involvement. Businesses, government offices, educational institutions, recreational spaces, and public transport were shut down with immediate effect. While the educated middle class stayed at home, there was widespread panic, especially among the massive population of migrant working class people stranded in their places of work (Pandey 2020). The next few weeks witnessed a large-scale exodus of migrant workers from the cities, many of whom were rendered jobless due to their workplaces' immediate closure. They walked hundreds of miles to their villages, with a few hundred meeting with death due to starvation, financial distress and road accidents (Mishra 2020). By the end of March, a completely new reality had set in, with local authorities grappling with directives that explicitly instructed them to resort to violence and coercion to ensure safety (Koride 2020). This period also witnessed xenophobic attacks on people from North-Eastern India because of their East-Asian features and their presumed closeness to China (Kolney 2020) and Islamophobic social media campaigns due to a COVID outbreak in the Tablighi Jamaat congregation (an Islamic missionary convention) held in New Delhi where thousands of foreign delegates were present (Perrigo 2020). "Work from home" became the norm for white-collar workers, and education shifted online, with only a privileged minority possessing devices like a smartphone or laptop being able to access it. It is in this reality of social, economic, and environmental inequality that educators and researchers need to situate their work regarding global pandemics. Science education is situated at the nexus of power relations; as can be seen when dealing with deadly viruses at the level of populations. Critical educators need to turn their attention to both the 'macro' and 'micro' politics of COVID-19, because these are linked to both the science of COVID-19 (viruses and transmission) and biomedicine informed health policy (how science informs governance of a community or population).

In this article, inspired in part by Rezende et al. (2021) vision of a post-pandemic science education informed by southern epistemologies, we outline a theoretical and methodological context for examining educational discourses surrounding COVID-19 from a critical sociopolitical perspective. More specifically, we aim to make the knowledge politics around pandemics, medicine and health in India, and elsewhere, more visible through an analysis of health education material aimed at pandemic awareness in India. However, for us, the concepts/themes that thoroughly link a discussion of education, science, politics and pandemics are subjectivity and (bio)power.

The pandemic by itself changes little about the political contexts of science education. However, we believe that some critical orientations and coordinates surrounding subjectivity and power may shift slightly in light of COVID-19, such as the subject's intimate attachments to power, collectivity, and control (which we discuss briefly near the end of this paper). It simply exposes how science education is integral to the governing of modern subjects in terms of how it comes to bear on the conduct of conduct. As the paper progresses, we will endeavour to develop this relationship between science, (bio)power, governance and education. Drawing from Michel Foucault's conception of (bio)power, we emphasize the importance of subjectivity, and its formation, in the context of pandemics. 
As authors, we (Aswathy and Jesse) have combined our shared interest in the dynamics of knowledge/power and education to explore what it might mean to trace the 'subject of COVID' as well as the stakes for new (and old) desires and attachments this subject might embody. Like many others, we are interested in the productive and perhaps revolutionary potential unleashed by the contingencies of COVID-19, whilst acknowledging the many dire contexts most people face as part of early mid-twenty-first-century life.

\section{Biopolitics and the COVID-19 pandemic}

The response to the COVID 19 pandemic on the part of nation states across the world is a textbook example of the exercising of what Foucault calls biopower (Foucault 1990). According to Foucault, modern Western nations witnessed a shift in how the nation state exerted its power over subjects in that the exercising of power became more diffuse over the unfolding of life itself. The rise of biopower involves "the entry of phenomena peculiar to the life of human species into the order of knowledge and power" (Foucault 1990, p.142). Increased agricultural productivity, the development of different disciplines of knowledge related to life, and the associated techniques of measurements and appraisal of various aspects of human production and survival helped consolidate biopower. Biopower operates along two poles simultaneously. The first pole is the "anatomo-politics of the human body" and is centred on the body itself-its disciplining, the optimization of its capabilities, the extortion of its forces ... its integration into systems of efficient and economic controls". The other pole is the "biopolitics of the population" and focusses on the population and controlling and intervening in biological processes like "propagation, births and mortality, the level of health, life expectancy and longevity, with all the conditions that can cause these to vary" (Foucault 1990, p.141). While Foucault's work is sometimes ambiguous about the difference between biopower and biopolitics, we take the view of Hardt and Negri (2000) that understands (bio)power as the fruition of the controlling aspects of modernity that harnesses the productive power of life. Biopolitics takes into account the agonistic relations of resistance 'from below' that accompanies all power relations. For the purposes of this paper, this distinction is not crucial.

In the context of the pandemic, one witnesses biopower being exerted along both the poles with government directives and notices explicitly demanding appropriate health behaviour on the part of the individuals, and the imposition of lockdowns, curfews, and police brutality on populations. However, the interventions into the life of 'populations' are also formed, in part, by resistance and creativity from below-in fact, Foucault is insistent that as far as power relations are concerned, resistance and freedom come first (Foucault 1982). In other words, while communities will be locked down and quarantined, and indeed sometimes desire to be controlled this way (Samuel, Chakraborty and Joy 2020), the practices of governance are also shaped from below by the people. It is more helpful to understand biopolitics as resistance, and also creation, of the forms of life that are the target of governance. As educators face more chaotic ecological and social events, like pandemics, how power shapes the conduct and subjectivities of individuals through education needs to be a part of the larger conversation.

In this paper, we take Rabinow and Rose's (2006) view of biopower as truth discourses, strategies of intervention and modes of subjectification, invoked by various sanctioned authorities, about the 'vital' character of human beings-which includes the power to 'make live' and 'let die'. Science education is in one way biopower that is both exercised 
and resisted 'from below' (biopolitically). Kirchgasler's (2018) work on race and American colonialism, as an example, demonstrates how science education can be used as an intervention into the lives of 'disposable'/colonized peoples. It is this more focussed definition of biopower, one that directly pertains to the life sciences and medicine, and one that is 're-activated' with the discourses surrounding COVID-19 and pandemic education that helps us (Aswathy and Jesse) imagine how discourses of health education are completely co-extensive with a sociopolitical reality that constitutes particular kinds of subjectivity.

With so much discourse about mortality, immunity, and the ethics of livability and community, we believe that it is important for educators to revisit questions about science and its relation to the governance of life. While biopower consists of multiple forces, strategies, and institutions that govern life, we propose that calling attention to authoritative discourses is something educators can engage with directly and immediately. The dominating discourses of the biomedical sciences strongly shape the shared reality of the COVID-19, but also how we come to see ourselves (subjectivity) in relation to the pandemic. This is evident in the measures taken by the state to contain the spread of the virus and the notices issued by the World Health Organisation and health ministries/departments in many countries world-wide (Han 2020). In India too, while the discourse of biomedicine is invoked time and again by the Ministry of Health to institute social distancing and enforce the compulsory use of face masks, the Indian state also supports the use of alternative medical systems (such as Ayurveda, Unani, Siddha and Homoeopathy).

In the following section, we examine key questions and constellation points around power, governance, and subjectivity. What kinds of methodological, theoretical, sociopolitical, and ethical possibilities does the COVID-19 context present to critical research into relations of (bio)power and the (re)production of subjectivity? While we do not nearly address all of these fissures and folds in this article, the following section is a window into our starting point for thinking about COVID-19, subjectivity, and governance in different national contexts. Ultimately, we chose to focus on India over Ireland, because of Aswathy's familiarity with educational resources already published, and to better understand our own theoretical perspectives in a situated manner. Once we have outlined a theoretical and methodological context for critical inquiry into COVID-19 and subjectivity, we will move to the problematic of science, educational discourse, and alternative medicine in India.

\section{COVID 19, discourse, and the (re)production of subjectivity}

When we began discussing the COVID-19 pandemic in the spring/summer of 2020, one of our first observations was that educational discourses about the pandemic were not only ubiquitous, but also largely unexamined. We also wondered how to begin: what limitations and constraints would we place on our exploration of the pandemic? What was possible to think at the time? We also pondered about whether the typical coordinates of critical analysis into discourse and subjectivity would change, or at least be jostled. However, after months of discussion and analysis, we came to realize that most aspects of critical analysis into discourse and subjectivity remain unchanged (at least to us). Methodologically speaking, researchers still need to examine how discourse works to constitute subjectivity through affordances, limitations, silences, imperatives, incitations, etc. We both agreed that, however, problematic it was to use a Western theorist to think about the context in India, Foucault's historical work remains useful, even foundational, to examining 
discourses of science and health education. But perhaps it is time to take up some of these older seminal works in different ways. The question on our minds as science educators is: what fissures and fault lines present themselves here and now when it comes to educational discourses about health during pandemic times? We discuss themes of biopower, science, and alternative health in India, leaving some material in this section for another paper (or for different people to take up).

Power relationships between the governing apparatuses of a nation state and its subjects will shift as the dangerous outcomes of capitalism and ongoing colonialism unfold. Still, any consideration of (bio)power must look beyond how power represses (Bazzul 2014a). With the understanding that the exercise of power is neither good nor bad, critical educators need to examine how power conducts conduct and attaches the subject to intimate aspects of themselves (e.g. the production of an Indian/Irish citizen and their attachment to this core aspect of themselves). Science and other objective knowledge are often employed when power is exercised; both from above and below. What should interest science educators is how science is employed in the conducting of conduct, (Foucault 1982).

Turning to Foucault's (1982) essay "The subject and Power" is useful for thinking about the stakes of global struggles with power in relation to healthcare, safety and security, living wages, livelihoods and ways of living, freedom and equality. The issues of power instigated by the COVID-19 pandemic are very similar to all popular struggles with power in that they:

1. Traverse national boundaries (stakes are global)

2. Are aimed at particular forms of conduct (stakes involve freedom and conduct)

3. Have to do with immediate actions to be performed (stakes involve everyday life)

4. Question status and identity of individuals (stakes involve subjection of some by others)

5. Employ objective knowledge (stakes involve how knowledge is constructed and used)

6. Re-define modes of being for people (stakes involve collective and personal attachments)

As Foucault noted, collective struggles with power today are both specific (they involve particular actions/freedoms here and now) and intimate (they involve those things people are most attached to). In this paper, we suggest that considerations of discourses around COVID-19 exceed national boundaries (exceed the Indian context); involve the control of everyday conduct; employ objective knowledges and intimate aspects of our identity (national or cultural backgrounds); and involve a redefinition of life and existence in the face of the pandemic.

COVID-19 has not changed anything, but has effectively (re)activated the awareness of agonistic power relations and the struggles with/against them on a more widespread level. While there is obviously much more to say about relations of power, we feel one important place to start is in the constitution of 'subjectivity' through discourse and (bio)power. The general questions we want to begin asking, first perhaps in the Indian context, but also globally, are the following: 'Who' is the 'subject of COVID-19'outlined by educational materials that teachers the general public uses as guidance around COVID? How are discourses of science education integral to constructing this subject? What new coordinates or lines of intelligibility are evident in the biomedical/educational discourses around COVID 19? What kinds of subjectivity do biomedical/educational discourses around COVID-19 help constitute or make possible? How are the aims of governance connected with discourses of power/knowledge, and what forms of resistance/creation might come to exist? We are also interested in what the existing tensions between Western Science and AYUSH 
in India might tell us about relationships between knowledge, governance, and collective agency.

\section{Critical discourse analysis of pandemic awareness material}

In this section, we outline the general method of discourse analysis methodology used to analyse COVID-19 awareness materials created by a collective of Indian STEM professionals (Indian Scientists Response to COVID-19). Overall, our approach to analyzing discourse is derived from Foucault's archaeological method, which examines a set of discourses as a kind of cross section of a particular discursive 'regime', or social reality, in a particular time and place. The social reality outlined in discourse, as well as practices and the material distribution and structure, includes the essential modes of being for a subject in terms of conduct, attachments, ethical commitments, and key aspects of the self. This also happens through silences or what a discourse does not say, allow or make visible. An archaeological study can be large or small depending on the number of documents, or other sources of discourse, used to elucidate a particular social location or reality. The analysis undertaken here is small because a lot of room has been dedicated to working out theoretical and methodological points before here at the beginning of our joint inquiry into educational discourse around pandemics, public health, and governance. For a more elaborate explanation of the methodology employed here, see Jesse's (Bazzul 2014b) paper on critical discourse analysis and science texts.

One of the first things that needs to happen in an archaeological analysis is for a limitation to be set in terms of what samples of discourse/documents will be examined. This limitation happens through a convergence of choice, researcher capacity, and extraneously imposed limits. It is through this limitation that the borders of the analysis, what might accomplish, becomes visible. In this case, we have limited ourselves to education discourses of pandemic awareness material created by a collective of Indian STEM professionals meant to act as scientifically informed public health guidance. These consist of illustrated graphic narratives and pandemic awareness posters that exemplify correct behaviours and attitudes people should embody in relation to COVID-19 awareness and prevention. These narratives are meant to be accessible and relatable to large sections of the Indian public.

Our archaeological method, derived from Foucault, views discourse as widely circulating statements that define the objects, and subjective positions, that can be spoken about (Mills 1997). The statements that comprise discourses are utterances with institutional force or authority, such that they are perceived as being 'in the true' (Foucault 1972). That is, statements are granted a certain truth value by a disciplinary backdrop of truth/power that justifies a particular statement or set of statements. This relationship exists regardless of whether something is 'actually true' - all that is needed is for a statement or discourse to be perceived as true or 'in the true'. In modernity, a statement's real or perceived 'scientificity' matters when assessing how much power it may exercise (along for many other reasons). Our stance here is completely compatible with a realist stance on knowledge as we do not maintain that political power (biopower) determines knowledge. Rather, we maintain that there is always a set of relationships between science and government or truth and power (Foucault 2003a, 2003b).

On account of the fact that discourses, made up of statements backed by institutional legitimacy, circulate in the wider social world they therefore do not 'belong' to any one person or small set of persons. This means that when examining documents, 
especially those that claim to have no specific author (like government documents from India), it is useful to 'drop the author' function. In other words, suspending, as much as possible, the idea that a statement's qualitative character originates from a solitary individual. For example, when critically reading Indian health education material aimed at pandemic awareness, we assume their discourses largely consist of wider prevailing discourses in India in relation to health, politics, and the cultures of science. Shifting importance away from individual authors also allows researchers to explore related statements across a wider variety of texts, as well as attaching greater sociocultural, political, and ethical importance to texts written by one set of authors. It is very likely that the discourses found in these Indian government documents would surface in other discursive locations related to science and governance, albeit in different forms.

Another technique we employ that is somewhat related to the 'dropping the author' function is the 'reading at the surface' of the text. This means, as much as possible, not trying to intuit some kind of other intention to statements than the apparent one on the surface. This way of reading attempts to 'free', as much as possible, statements from the assumptions of the reader, but also the writer. (Again this is related to dropping the author function point above.) The purpose of critical discourse analysis from an archaeological perspective is to find relations between statements regardless of the authors' intentions. There are most certainly other potential meanings of statements, but the goal of this type of discourse analysis is to find regularities that exist across statements and across discourse(s). Employing this technique also implies that any text is not, in itself, a totality or unitary whole that is completely unique onto itself. Discourses within texts can never entirely be self-referential (interestingly texts that purport to be beyond criticism, like the Old and New Testaments, claim this feature). Reading the surface level of the text also helps negotiate what Kendall and Wickam (1999) call second-order judgements: those judgements by the analyst that come from some other sociopolitical viewpoint, historical reality, society, etc. While it may not be possible to get rid of second-order judgements altogether, the technique of reading the surface of the text helps minimize the influence of these judgements when reading the literal surface of the text to see how objects and the contours of subjectivity emerge. (which was especially useful in the historical work Foucault undertook).

Finally, we maintain that discourses in a particular social location work to constitute particular subjectivities by making some actions, thoughts, and outlooks thinkable, doable, or realisable. This happens through the allowances, limitations, attachments and practices outlined within discourses; of course recognizing that discourse is only one of a number of ways of shaping subjectivity. For Foucault, the target of modern systems of governments are bodies, but more specifically the (re)production of subjectivity. Subjects are not just a target of (bio)power that circulates in (truth) discourses, they are also an effect of biopower. Subjects do not present as a blank slate ready to be shaped, subjects always already exist as the result, or effect, of many discourses, practices, and material relations (Butler 1997). Discourses also outline those institutions and strategies of power that act on individuals in terms of how they exercise power, for what purposes, under what conditions, by what calculus, and make possible certain modes of life/living. This methodology/method guided our critical analysis of the pandemic awareness material developed by the STEM professionals' collective in India which we discuss in the following section. 


\section{The subject of COVID in Indian pandemic awareness material}

In India, the Ministry of Health and Family Welfare (MoHFW) largely undertakes the formulation and execution of health policy, which is primarily based on biomedicine/allopathy. The department of AYUSH (Ayurveda, Yunani, Siddha and Homoeopathy), formerly a department within MoFHW, catered to promotion of indigenous and alternative medical systems for healthcare. However, since 2014, which coincides with the Hindu nationalist party, the Bharatiya Janata Party, coming to power, a separate ministry of AYUSH was established to promote alternative and indigenous medical systems in India, following which the budgetary allocation to the AYUSH department also increased (Budget 2019). Since then, there have been several controversies around the 'scientific' basis of some advisories issued by the AYUSH ministry (Rathee 2018). During COVID 19, both the state ministries have been issuing advisories. The MoHFW website, for instance, has awareness material (posters, notices and audiovisual material) mostly directed at inculcating appropriate health behaviour that is based on a biomedical understanding of the disease. There are several advisories urging the public to wear masks (including directions on how to make reusable cloth masks), wash and sanitize hands, maintain physical distance, avoid crowded spaces and avoid spitting in public spaces (MoFHW 2020a). The website also carries numerous advisories urging the public not to discriminate against or disrespect COVID 19 patients as well as the frontline workers referred to as "corona warriors" who include healthcare workers (doctors and paramedical professionals), sanitation workers and the police (MoFHW 2020b).

In this section, we discuss how the 'subject of COVID-19' is constructed through biomedical discourses in educational material for pandemic awareness created by Indian Scientists' Response to CoViD-19 (ISRC), a collective of Indian STEM practitioners affiliated to eminent research institutes in India and abroad. According to the website (ISRC 2020a):

Indian Scientists' Response to CoViD-19 (ISRC) started as a group of Indian scientists who came together voluntarily in response to the COVID-19 pandemic. It has now grown to include more than 500 scientists, engineers, technologists, doctors, public health researchers, science communicators, journalists and a number of students; they hail from a range of disciplines but principally the physical and life sciences; they are affiliated to eminent research institutes of science and technology, universities, colleges, hospitals and private laboratories. The group also includes Indian scientists from laboratories all over the world.

Though the ISRC material is not issued by the Indian government, its discourse carries the authority of the scientific/biomedical establishment in India and is linked with power through its exclusive claim to truth and objectivity. The ISRC website carries evidencebased scientific information on COVID 19 collated with the purported aim of informing policy and was arguably one of the best sources of health advice available to the Indian public to deal with COVID 19 in the initial few months after the lockdown. The awareness material includes graphic narratives, posters as well as public statements. Most of the material has been translated into several regional languages. There are sections exclusively devoted to scientists and working professionals, the public as well as teachers and students. The educational material in the website, similar to that of the MoHFW material, aims to generate awareness on COVID 19 in India. However, as we discuss below, they also mirror the sociopolitical realities of a society organised around hierarchies of class, caste, gender and ethnicity and religion which is also impacted by the global neoliberal economy. 
The purpose of this analysis is not to reject norms and rules such as wearing masks or social distancing measures, as they are necessary to maintain public health, but rather, to point to the ways through which biopower operates in science and science education discourse. More specifically how the discourse of these educational materials, which also simultaneously act as biomedical discourses, outlines a particular subjectivity. The educational material presented in the ISRC website ranges from posters to didactic texts to graphic narratives and is available in English and regional languages.

Our analysis of the ISRC material suggests that the ideal 'subject of COVID' outlined in this material is one who accepts the biomedical model of health and disease and conducts themselves in accordance with state-sanctioned rules and norms. As discussed above, the target of biopower often has to do with conduct. This conduct is very often solidified by activating a series of attachments 'within'. In this case national duty and adherence to a scientific (or proper) worldview. This subject is a caring and responsible citizen who supports and educates their family and friends regarding COVID 19, but also one who accepts high levels of risk and wealth inequality. The discourse also works to construct acceptable science-abiding citizens of communities who have been 'othered' by majoritarian politics (muslims and the working class bahujan). We further discuss these observations below.

\section{The caring, responsible and science-abiding citizen}

The "caregiving story" from the ISRC website is (ISRC 2020b) a fictitious narrative of a south Indian working class, uneducated family of five (likely dalit-bahujan though not explicitly mentioned in the narrative) which has a first generation learner, a little girl Sumathi. The father-in-law of the household contracts COVID 19. The story revolves around how the little girl Sumathi, armed with her knowledge of science helps her family understand what "that corona (virus)" is and how to help her grandfather recover from the illness by convincing them to buy a thermometer and making arrangements for physical distancing in their cramped quarters. There is also a strong critique in this narrative of the inadequate public health infrastructure which makes it difficult for many like Sumathi's family to access good health care. The narrative suggests that these conditions notwithstanding, members of a family could come together and through the implementation of scientific safety measures and coordinated planning, overcome all odds to survive the illness. The use of the family as an instrument of medical intervention can be seen in the following passage:

Grandfather remains in the isolation room, only coming out to go to the toilet. Manikam takes over Sumathis job of taking Grandfather's temperature regularly. When he does that everyone else keeps a safe distance from him. Ganesh has drawn chalk lines on the floor for Grandfather's passage and circles for who should be where

There are a few things to note here. First, the instructions for spatial layout of the family home, complete with partitions that divide and isolate the sick and contagious from the rest of the family unit. Second, the translation of family care into labour tasks or 'jobs' which are largely aligned with the traditional gender roles of a patriarchal family, wherein the woman is the primary caregiver. Third, and this is a point for all the narratives, the language of a story or narrative is translated into an instructional discourse, as if the family's actions were analogous to government health instructions. While this is precisely the point of the narrative, what we are trying to do is make the commonsensical seem specific or contingent. In this case, we are trying to emphasize the governance of bodies through 
the family as an organizing device for separating the sick from the healthy and maintaining patriarchal roles and relationships. In other words, to be critically aware of the direct relationship between (bio)power and the family through biomedical/educational discourses.

Similarly, the "Going out story" (ISRC 2020c) of Abdul centres on a lower middle class Muslim family who live in a one room home. The story revolves around scientific and safe behaviour that a person must follow when going out to purchase groceries or other essential items. The protagonist of the story, a college-going student named Abdul, follows all the norms in one such errand which involves a trip to the mutton shop and back. The narrative, like the other stories, draws attention to the socioeconomic conditions and cultural habits of the characters. For instance, where there are pointed references to the cultural practices of muslims such as the practice of namaz, the mention of the mutton shop (to emphasize non-vegetarian food habits), and the employment of kinship terminology such as ammi and $a b b a$ when referring to Abdul's parents. Through a juxtaposition of the scientific behaviour of Abdul and his family and their cultural habits, the discourse works to suggest that rational scientifically informed behaviour can redeem anyone.

While to some readers, the discourse of "The going out story" may appear inclusive, it may also help to examine the secular tendencies in the discourse. Secularism is an important ideology that fuelled modern Indian nationalism. Western secularism has its roots in the nineteenth century which sought to differentiate the political sphere from the religious sphere, through the separation of the public sphere (the realm of rationality) from the private sphere (the realm of faith) (Pantham 1997). However, the Indian version of secularism also emphasizes tolerance or respect for all religions, while retaining the political/religious or public/private distinctions. While the 'Going out story' acknowledges a minority religion, the discourse in the story also emphasizes the private lives of Abdul's family, where religious markers assume a central focus, for instance, the father performing namaz and wearing a skull cap (Fig. 1) is conspicuous in the image. However, when Abdul steps out, he becomes a science-abiding citizen who leaves all his religious markers behind.

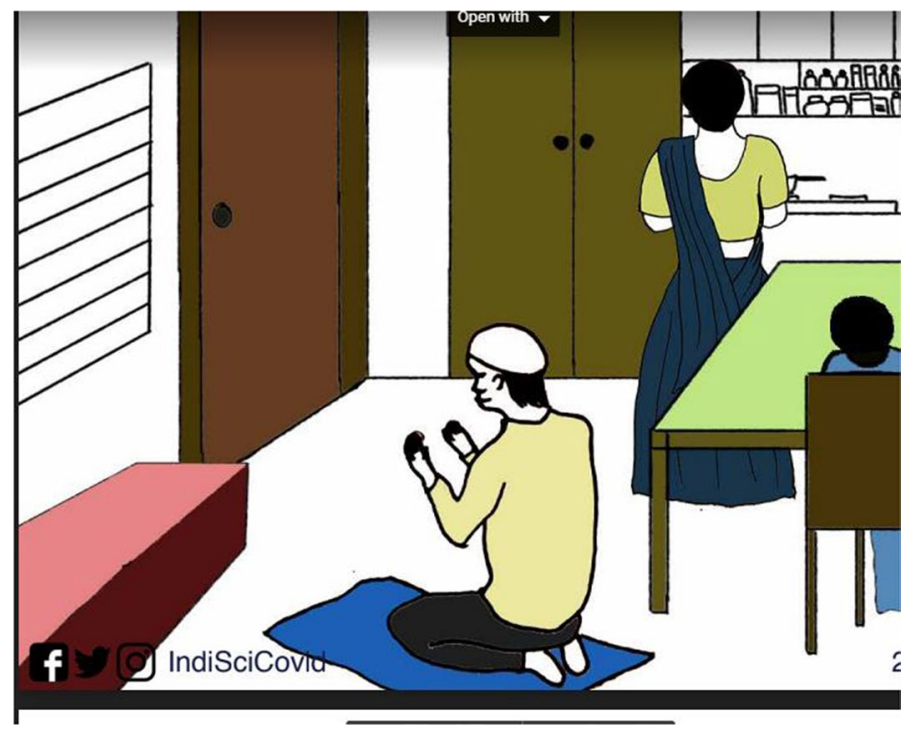

Fig. 1 Religious markers assume prominence in the "going out story" 


\section{The risk embracing COVID 'warrior'}

What the pandemic makes clear is that both wealth and risk are unfairly distributed in society-yet risk inequality is fully known and even sanctioned by (neo)liberal economies. This is evident in the narratives "delivering goods" (ISRC 2020d) and "working in a shop" (ISRC 2020e) that are addressed to delivery persons and shopkeepers, encouraging them to follow safety measures. The narrative "delivering goods" elevates the young delivery man Karthik to a superhero as he circumvents all difficulties to deliver food and milk during the lockdown. It's useful to keep in mind that issues of labour and global finance during the pandemic traverse any national boundary (just like the virus). His wife and he work together as a unit and devise ingenious tactics to ensure his safety. Similarly, in the narrative "working in a shop", the protagonist Govindan Nair and his son conceive of ways to safely sell the items in their grocery shop. The narratives present the precarious labour as heroic, but unproblematic. As can be seen in the following passage from "delivering goods":

"You can still go out during this lock down. How lucky!" remarked Laila, who was bored of sitting at home, with not much work to do. Both were staring at Karthik cleaning his scooter outside after his last delivery.

The pandemic has rendered delivery people and health care workers highly vulnerable. Their precarious work conditions put them at a much higher level of risk than others. Karthik the delivery person is a superhero, but only because he does his job.

"The going out story" and the "delivering goods" narratives also remind the reader of two things: first that health interventions are co-extensive with socioeconomic conditions sanctioned by the state apparatus and second that many health directives of the state are directed mainly to/for the poorer segments of the population. Again, our point is not that health interventions should not be aimed at the poor, rather our aim is to draw attention to the fact that discourses of health and prevention circulate the effects of (bio) power by conducting conduct in relation to health and economy (economy here seen its widest meaning). For example, it is easy to see how health and economy are linked in the following passage where Abdul speaks with the owner of a mutton shop.

It was nice to talk to someone in person outside his family, even if they were shouting across the shop, and even if the conversation was muffled by their masks. "Ya ya, everyone at home is well. Just a bit worried, that's all. I don't know about this lockdown Chacha! Seems like this is going to go on for a while. Not sure what the plan is!" Abdul replied. He lingered a few minutes more and chatted with Karim Chacha about the current economic scenario.

It is not that it is strange to speak about economics, or that economics would find their way into a conversation during pandemic times, it is simply that this discourse has indicated that there is a singular economic scenario to speak of. While this is not the overall goal of the narrative, this is one instance where a power-infused health discourse speaks of a singular economic viewpoint. As the reader, we are given no details about the scenario, however, we are made to understand that there is one global economic scenario that we are meant to take as reality. All the narratives taken together outline little to no economic support for families, and in this way show that the economic scenario meant to be taken as reality is a neoliberal economic reality that leaves people to largely fend for themselves (Harvey 2007). This neoliberal economic reality where the state 
relinquishes responsibility for citizens can also be seen in the caregiver story where Selvi considers going to the hospital.

How will they even go to the hospital? They say the ambulance will come and take you, but will ambulances come for poor folks like us, she worries. One of the families she works for (worked for?) has an old lady about whom that family is worried; surely the ambulance would come for her. Even if the old man gets taken in an ambulance, how will Selvi take food so many times a day to him, when there are no buses? Can she trust the Government to give him food regularly? What she has seen of the hospital does not inspire confidence in her.

It may very well be that the hospital situation for many families in India is not viable, but it is interesting to note how government health discourse shirks the responsibility of regular meals in hospitals. The message seems to be that the sick will be better cared for at home. And while this may very well be true, it is noteworthy that the government foreclosed the possibility that they would make the situation better during the pandemic. A specific relation of people to the government is being stated: 'Don't rely on us for help. We are not capable. Rely on yourselves'.

\section{Science versus pseudoscience: biomedicine versus AYUSH?}

A conspicuous feature of the educational and scientific discourse of the ISRC website is the binary that it invokes between biomedicine and traditional systems of medicine and "home remedies" (ISRC 2020f, 2020g, 2020h, 2020i). The COVID-19 pandemic has rekindled an age-old onto-epistemological debate around medical knowledge systems in India. This arguably began with the government of India involving the Ministry of Ayurveda, Yoga and Naturopathy, Unani, Siddha, and Homoeopathy (AYUSH) in its strategy for COVID management. When the first case was reported in India in January, the AYUSH ministry issued an advisory advocating the use of Unani and Homoeopathic remedies (AYUSH 2020). This advisory met with severe criticism from allopathic doctors, scientists and rationalist groups (Groups committed to curbing superstition and backwardness through the spread of science in India), wherein suggested remedies were dubbed as "myths" and "placebos" (Priya and Sujatha 2020). In April 2020, an Interdisciplinary AYUSH research and development task force for COVID 19 was set up to collaborate with existing research and development organisations, industry and the state governments to develop preventive and therapeutic approaches. Some states like Kerala and Tamil Nadu set up Ayurveda and Siddha-based response cells (Priya and Sujatha 2020). In early October, the union minister of health released Ayurveda and yoga-based protocols for management of coronavirus disease (Covid-19) for treating patients with mild symptoms. This was met with severe criticism from the Indian Medical Association, a voluntary organisation of doctors representing scientific medicine who asked if the suggested measures were backed by double blind controlled studies (Kaul 2020). After several heated exchanges between advocates of biomedicine on the one hand and alternative medical practitioners on the other, very recently, the ministry of AYUSH submitted to the supreme court of India that AYUSH practitioners may prescribe only "immunity boosters" for COVID and no drugs to cure COVID (Sinha 2020).

Priya and Sujatha (2020) point out that indigenous systems of medicine such as Ayurveda, Siddha and Yunani medicines have had a long history of helping manage epidemics, especially in the early twentieth century, though the principles of treatment are not based 
on germ theory. Critical scholarship of social scientists and scholar-practitioners of these alternative medical systems draw attention to how the onto-epistemological principles on which these systems are based are different from that of biomedicine (Sujatha and Abraham 2012), though they caution against an oversimplified othering of these knowledge systems in relation to western systems of medicine (Sujatha 2007). Alternative medical systems, despite catering to the needs of a large population of people, have been subjected to the challenge of proving their efficacy using the standards of biomedicine such as placebocontrolled double blind tests, when the very epistemological principles on which these systems are based are incompatible with testing through RCTs (Sujatha 2007).

It is also important to note that the aforementioned onto-epistemological debate between biomedicine and alternative medicine has been complicated by the Hindu nationalist appropriation of AYUSH which seeks to forge continuities between science, religion, tradition and modernity (Kumar 2020). At this point, one may want to ask after what connects these tendencies - the appropriation of science to validate nationalist agendas on the one hand, and the scientistic disavowal of anything "traditional" or "religious" on the other.

\section{Science and the postcolonial subject}

Certain aspects of the educational discourse for pandemic awareness in India discussed resonate with a particular 'liberal progressivist' position on science (Chadha 2005). This liberal progressivism is characterised by a commitment towards 'scientific temper', a faith in science and technology-based path to development, progress and social upliftment. According to David Arnold (2013), the nationalist leader Jawaharlal Nehru lent 'authorial voice' to this discourse seeking to rebuild postcolonial India on a certain image of science. Scientific temper was for Nehru a philosophical ideal that helped justify some of his social and political positions such as scientific socialism and a secular world view (Arnold 2013). Scientific temper was believed to be the antidote to the social 'backwardness' prevalent in a society that was plagued by poverty, ill-health and overpopulation. Nehru also believed that international cooperation through science is a route to postcolonial sovereignty. Nehru believed that scientific planning in areas such as population, health, manufacturing was important for India's growth and development. However, this faith in science was coupled with a strong scepticism of superstition, tradition and everything unmodern. Nehru's notion of scientific temper held widespread appeal during his time and later, especially among scientific elites, intellectuals and Marxists. Article $51 \mathrm{~A}(\mathrm{~h})$ of the constitution of India (Bakshi and Kashyap 1982) also mentions that "to develop scientific temper, humanism and the spirit of inquiry and reform" is a fundamental duty of a citizen of India. Many groups committed to the spread of science and rationalism have since interpreted and used this concept in diverse ways.

In her recent book, Banu Subramaniam (2019) argues that biopolitics in India constitutes “... a layered history of the precolonial, colonial, and postcolonial. It is in part shaped by Western practices of governmentality, institutionalized through the British Empire during colonial rule but also through biopolitical practices deeply embedded in local practices and religions (p.13)"'. Medicine is one among the many sites through which biopower operates. And as we see from the above discussion, the COVID 19 pandemic and its management in India have rekindled not just an academic debate, but a fundamental questioning of what it means to care for oneself in these times. How does the layperson negotiate the conflicting government advisories advocating both biomedicine and AYUSH-based cures? 
Medicine and culture are entangled in complex ways. Leena Abraham (2009), in her work on Ayurveda in Kerala, discusses how Ayurveda has a pervasive and 'embodied presence' in the everyday lives of the people and its knowledge is employed in mundane activities such as cooking, bathing and grooming. This happens to be the case despite the enduring presence of a strong people's science movement (The people's science movements emerged in India in the period following independence from British rule. These movements were committed to the popularisation of science and the inculcation of rational outlook among the Indian masses. Kerala was one of the first states where such a movement emerged and had a deep impact on the people.) and a high premium placed on science education placed by the state. In the context of the pandemic and the re-animation of the debates on medicine, it is important for educators to examine whether and how these epistemological conflicts impact the practices and health care decisions of the ordinary person. As mentioned above, the stakes of biopower, and biopolitical resistance have to do with a subject's everyday material circumstances and/or the practices of daily life.

While we speak mostly of the Indian context in this paper employing the framework of biopower and biopolitics, similar work in other cultural contexts may reveal important areas requiring intervention on the part of critical educators. As Rezende et al.'s (2021) article also demonstrates, the pandemic has also unveiled deep-seated cultural and structural inequities in Brazil.

\section{Social medicine and 'Noso-politics': medicine has always been political}

The COVID-19 pandemic provides the everyday person a glimpse into the social-economic-political 'body' that is the object of socialized health systems in modern societies. While people definitely rely on these systems, even praise them (rightfully), educators should exercise caution in believing that systematized medicine is, at its very core, wholly benevolent. Besides all the good outcomes of the biological and biomedical sciences, its rise was, and arguably still is, linked to efforts to purify, control, administer, 'harness' populations for purview of the state (Murphy 2017). Such systems have also played a colonizing role in the (bio)medicalization of certain populations, threatening their sovereignty and very existence. A present day example of the erosion of a people's autonomy and selfdetermination can be seen in the Eurocentric mapping of Indigenous DNA onto colonial ideologies and structures (Tallbear 2013). Many of Foucault's writings and historical analyses outline how and why populations become the object of modern governance, and in this discussion, we outline one line of thought in relation to 'social' medicine and 'nosopolitics' (the politics of disease) (Foucault 2003b). We recognize the problematic nature of using a theorist like Foucault, and the assumption that European histories are automatically relevant to regions like South Asia, etc. This discussion therefore may be wholly irrelevant to discussions of health, science, education and governance in other contexts, even counter-productive.

In Western countries, the eradication of diseases like smallpox can be traced to the concerns of elites and the perceived need for massive urban sanitation projects and thereorganization and 'sanitization' of the urban poor themselves as potential bodies for labour and war (Foucault 2003a). The anxiety of the upper classes re-deployed epidemic planning techniques, such as quarantine measures to categorize and monitor the urban poor. It is tempting to view a socialized medical system as the epitome of state care and concern, and to some extent, it most certainly is a valuable mode of care. However, it is also true that the 
reason(s) such systems were created in the first place was to protect the health and property of privileged elites by compartmentalizing, surveilling, and implementing hygienic and behavioural regimes on large swaths of society. Fredrique Appfel Marglin's work on the introduction of vaccination drives by the colonial administration in India to control smallpox also highlights how indigenous practices of disease control such as variolation were violently repressed (Marglin 1990). Thus, the 'biohistory' of biomedicine also involves relations between microbes, microbiology, and colonial aspirations. It would be incorrect to assume that Western biomedicine emerged around the private relationship between doctor and patient; the reality is that these medical systems were primarily developed as a complex series of social and community practices. It is capitalism that redoubles the focus on human bodies as sites of productive power. As Foucault (2003a) puts it, "For capitalistic society, it was biopolitics, the biological, the somatic, the corporeal, that mattered more than anything else. The body is a biopolitical reality, and medicine a biopolitical strategy" (p. 321). It has never been a simple matter of increasing the labour power of a population, but a much more detailed effort to increase a state's political, social, and economic capacity relative to its neighbours at every level.

In the age of pandemics, it is important to keep in mind that measures like lockdowns and quarantines are an important part of public health measures, but also operate as political-economic strategies defined by risk and the needs of a state. For better or for worse, the power wielded by state medical systems isolates and categorizes individuals in ways that call upon the subject to embrace the imperative to live-and in many cases to live so others can die. The point here is not to cast state medical systems as dubious, but to better estimate the political power of these systems of health. It is a matter of making them even more worthy of our attention as educators. The purpose of this discussion is not to sufficiently outline the relationship between medicine and governance. Rather, the purpose is to reinvigorate questions related to science, (bio)power, health and education in an age where government protection and intervention seem to be the only viable response to ecological disturbances, food and water shortages, mass draught and extinction. So, while some may be tempted to relegate these concerns to medical history alone, social medicine today would not be recognizable without the disciplines of chemistry, architecture, political economy, microbiology, urban planning, and education. It is education that makes the deployment of state medicine thinkable and possible. This is evident in our analysis of the pandemic awareness material and government advisories.

What seems most pressing about pandemics, and other health crises of our time, are the ways different bodies get caught (differently) in the circuits of power and resistance (Bang, Warren, Rosebery, and Medin 2012). There are those who resist medicalization and demand access to health services - the right to live and flourish — as they are intricately tied to socioeconomic and racial inequalities. For example, Tina Sacks' (2018) work demonstrates how encounters in the US healthcare systems are fraught with bias, disparities in treatment, and racial stereotyping. Educators should not be so quick to dismiss those criticizing or questioning state medical systems as 'crazies' or 'fundamentalists' when those same systems have historically targeted the poor, marginalized, racialized and colonized to serve a particular class, in-group, race, or centre of power (see Stoler 1995). While practices like social distancing and hygiene are important, it is also true that these practices (re) cast who should and can remain within circuits of productivity and under which conditions. While this might seem to be another topic of discussion altogether, it is partly out of apprehension for the poor and racialized/colonized minorities that populations become the object of intense focus and intervention whose aim was to standardize home and working life. Prescriptive health advice for families and schools is not new: COVID-19 simply 
draws our collective attention to the discourses and strategies of control employed by these institutions that call on each of us to respond with affirmation or resistance to this interpellating call.

The vaccine for COVID-19 presents itself at once as an issue of global domination, corporate-state ownership, and intellectual property. But vaccination has long been a hallmark of social medicine organized around the family as the "constant agent of medicalization" and the object of law, policy, and educational initiatives (Foucault 2003b, p. 344). As our analysis above shows, the family is central to the public health narratives published by the consortium of Indian STEM professionals. Doctors become sanctioned agents of care and expertise, but their utilitarian uses are not limited to the private relationships they have with patients. Indeed the space doctors occupy in healthcare systems is akin to that of teachers in schools-one that exercises biopower but also biopolitical resistance (e.g. are there enough doctors? Is their primary role to first treat those who haven't had access to healthcare?). Considering doctors act as agents of health and hygiene, their actions are also social, political, and economic. In the case of AYUSH health systems, a challenge for Indian society centres around who gets to occupy these respected positions of guidance and hygiene that medical doctors exclusively enjoy? What does it mean politically to include the expertise of the alternative medical practitioners alongside western medical professionals? These are not just questions of funding and labels; they are questions that potentially change the material, social, cultural and spiritual fabric of life in India today. While the circuits of modern governance and biopower remain much the same before and after COVID-19, we suggest that pandemics make visible a whole series of attachments and relations of power that exercise the power to make live and make die. The situation of health and governance must also take into account the way (neo)liberal ideology and practices have set limits on government actions in the name of the 'free markets' and/or civil society. Liberalism has made it so many of us cannot even imagine a government system that might put vital needs before capital and markets. Indeed, the Indian government consistently promises little in the way of government support. Educators can directly engage these contexts at the micropolitical level-how these relations play out through the discourses and practices of education systems when it comes to justice, public accountability, coloniality, and multispecies flourishing.

\section{Desire for communal forms of living}

One of the analytical questions that we find pertinent, but do not take up in this paper, is how a subject's desire for different (pastoral) relations of care, belonging, and even control and subjection may grow in precarious times of pandemic. Even if such attachments seem dubious or too convenient in light of what we know about governance and biopower. A desire to be controlled, subjected or even cared for, to be sure, no matter how 'healthy' or reasonable, would, like all desire, be 'captured' in 'interests'. In this case, the interest of safety and identification. All efforts to control beings involve harnessing or repressing desire, for better or for worse (Deleuze and Guattari 1988). A desire to be controlled would continually be (re)produced, or (re)activated, and repeated within a series of intricate power relationships that outline the stakes of life/death in relation to biopower. After COVID-19, more thought needs to be given to a subject's attachment to power, how it provides certain freedoms, and what this manufactured desire might say about the stakes of everyday life in places like India and Ireland. How would the desire for control and 
regulation form part of a subject's intimate attachment to themselves? How does this desire play out in power relationships that involve both ethical resistance and ompliance?

The pandemic may have provided a glimpse into the precarious conditions that will bring about new forms of collectivity in relation to power. It is not hard to notice new forms of solidarity and commitment to others through conduct, such as wearing face masks and social distancing. The desire for control and regulation seems more easily conjoined with new forms of collectivity; allin agonistic relations with state apparatuses and power centres that might provide some organization to these forms. For example, in India when NGOs and civil society collectives took up the responsibilities of governments (such as providing food to stranded migrant labourers) during the lockdown (Asadullah 2020). Slavoj Žižek (2020) in his book Pandemic!: Covid-19 shakes the world sees the exposure of a collective desire for communism(s) (plural). Not the failed twentieth-century versions, but something more imaginative, yet quite basic. At the heart of this collectivity are the values of equality, the fair distribution of resources, flexible and pluralistic scientific oversight, freedom to embody multiple practices of care, accountability, transparency, and collective wellbeing. This biopolitical relation between the multitudes on the ground and the centres of power and control may be a very long-standing one, but COVID-19 may have set the conditions for different collective coordinates to be articulated and expressed that always begin 'from below'. Resistance always comes first.

\section{References}

Abraham, L. (2009). Medicine as culture: Indigenous medicine in cosmopolitan mumbai. Economic and Political Weekly, 68-75.

Arnold, D. (2013). Nehruvian science and postcolonial India. Isis, 104(2), 360-370.

Asadullah. (2020). This Pandemic Should Help the Govt Acknowledge the Crucial Role. NGOs Play. The Wire. Retrieved From: https://thewire.in/rights/covid-19-pandemic-ngo-government.

Bakshi, P. M., \& Kashyap, S. C. (1982). The constitution of India. Universal Law Publishing

Bang, M., Warren, B., Rosebery, A. S., \& Medin, D. (2012). Desettling expectations in science education. Human Development, 55(5-6), 302-318.

Bazzul, J. (2014a). Science education as a site for biopolitical engagement and the reworking of subjectivities: Theoretical considerations and possibilities for research. In Activist science and technology education (pp. 37-53). Springer.

Bazzul, J. (2014b). Critical discourse analysis and science education texts: Employing foucauldian notions of discourse and subjectivity. Review of Education, Pedagogy, and Cultural Studies, 36(5), 422-437.

Budget 2019: In fillip to traditional medicine, AYUSH ministry gets Rs 1,939.76 crore (2020). The economic times. https://economictimes.indiatimes.com/news/economy/policy/budget-2019-in-fillip-totraditional-medicine-ayush-ministry-gets-rs-1939-76-crore/articleshow/70094965.cms

Butler, J. (1997). The psychic life of power: Theories in subjection. Stanford University Press.

Chadha, G. (2005). Towards an informed science criticism: The debate on science in post-independence India. In K. Ganesh \& U. Thakkar (Eds.), Culture and the Making of Identity in Contemporary India (pp. 247-258). Sage.

Deleuze, G., \& Guattari, F. (1988). A thousand plateaus: Capitalism and schizophrenia. Bloomsbury Publishing.

Foucault, M. (1972). The archaeology of knowledge (1st (American). Pantheon Books.

Foucault, M. (1982). The subject and power. Critical Inquiry, 8(4), 777-795.

Foucault, M. (1990). The history of sexuality, Volume I: An introduction. Vintage books: New York.

Foucault, M. (2003a). The birth of social medicine. In M. Foucault, P. Rabinow, \& N. S. Rose (Eds.), The Essential Foucault: Selections from Essential Works of Foucault, 1954-1984 (pp. 319-337). New Press.

Foucault, M. (2003b). The politics of health in the eighteenth century. In M. Foucault, P. Rabinow, \& N. S. Rose (Eds.), The Essential Foucault: Selections from Essential Works of Foucault, 1954-1984 (pp. 338-350). New Press. 
Han, L. (2020). Reading Chinese anti-COVID-19 pandemic narratives on facemasks as the art of disaster governance: A semiotic and biopolitical survey. Social Semiotics, 1-8.

Hardt, M., \& Negri, A. (2000). Empire. Harvard University Press.

Harvey, D. (2007). A brief history of neoliberalism. Oxford University Press.

Indian Scientists' Response to CoViD-19 (ISRC). (2020a). About us. https://indscicov.in/about-us/

Indian Scientists' Response to CoViD-19 (ISRC). (2020b). Selvi the caregiver. https://indscicov.in/2020/05/ 13/selvi-the-caregiver/

Indian Scientists' Response to CoViD-19 (ISRC). (2020c). Going out and returning home. https://indscicov. in/for-public/popularization-resources/going-out-and-returning-home/

Indian Scientists' Response to CoViD-19 (ISRC). (2020d). Delivering goods. https://indscicov.in/for-public/ popularization-resources/delivering-goods/

Indian Scientists' Response to CoViD-19 (ISRC). (2020e). Working in a shop. https://indscicov.in/for-public/popularization-resources/working-in-a-shop/

Indian Scientists' Response to CoViD-19 (ISRC). (2020f). The Hoaxbusters. https://indscicov.in/wp-conte nt/uploads/2020/04/English-02.png

Indian Scientists' Response to CoViD-19 (ISRC). (2020g). The Hoaxbusters. https://indscicov.in/wp-conte nt/uploads/2020/04/English-06.png

Indian Scientists' Response to CoViD-19 (ISRC). (2020h). The Hoaxbusters. https://indscicov.in/wp-conte nt/uploads/2020/05/26Hoax_Coconut-Oil_English.png

Indian Scientists' Response to CoViD-19 (ISRC). (2020i). The Hoaxbusters. https://indscicov.in/wp-conte nt/uploads/2020/05/20Hoax_Steam-Inhalation_English.png

Kaul, R. (2020).IMA questions the health minister releasing Ayush-based Covid-19 management protocol. Hindustan Times. Retrieved from: https://www.hindustantimes.com/india-news/ima-questions-unionhealth-minister-releasing-ayush-based-covid-19-management-protocol/story-YhMHKOU32tG2CXf q3pvbuL.html

Kendall, G., \& Wickham, G. (1999). Using Foucault's Methods. London, UK: Sage Publications.

Kirchgasler, K. L. (2018). Moving the lab into the field: The making of pathologized (non) citizens in US science education. Curriculum Inquiry, 48(1), 115-137.

Kolney (2020). Indians from the northeast face intensified racism as coronavirus fears grow. The Caravan. https://caravanmagazine.in/communities/coronavirus-increases-racism-against-indians-from-northeast

Koride, M. (2020). Lockdown violators should be shot at sight: Telengana CM. The Times of India Retrived from: https://timesofindia.indiatimes.com/india/lockdown-violators-could-be-shot-at-sight-telangana$\mathrm{cm} /$ articleshow/74801846.cms

Kumar, R. (2020). Face It: The Indian Government is peddling pseudoscience. The Wire. https://science. thewire.in/health/indian-government-pseudoscience-covid-19/

Marglin, F, A. (1990), 'Smallpox in Two Systems of Knowledge', in F.A. \& S. Marglin (eds), Dominating Knowledge: Development, Culture and Resistance, Oxford: Clarendon, 102- 144.

Ministry of health and Family Welfare. (2020a). Awareness material. Government of India. https://www. mohfw.gov.in/\#

Ministry of health and Family Welfare. (2020b). Salute to all Corona Warriors at the frontline of \#COVID19 response [video]. Youtube. https://www.youtube.com/watch?v=xMWe4UnykWc\&feature=youtu.be.

Ministry of AYUSH. (2020). AYUSH COVID 19 Dashboard. https://health.ncog.gov.in/ayush-covid-dashb aord/

Mishra, D. (2020). RTI Shows the Government Did Collect Data on Deaths of Migrant Workers During Lockdown. The Wire. Retrieved from: https://thewire.in/rights/centre-indian-railways-lockdowndeaths-migrant-workers-shramik-special-rti

Murphy, M. (2017). The economization of life. Duke University Press.

Pandey, V. (2020). Coronavirus lockdown: The Indian migrants dying to get home. The BBC News. Retrieved from: https://www.bbc.com/news/world-asia-india-52672764

Pantham, T. (1997). Indian secularism and its critics: Some reflections. The Review of Politics, 59(3), $523-540$.

Perrigo, B. (2020, 3rd April). It Was already dangerous to be muslim in India. Then Came the Coronavirus. Time. https://time.com/5815264/coronavirus-india-islamophobia-coronajihad/

Priya, R., \& Sujatha, V. (2020). AYUSH for COVID-19: Science or Superstition? Indian journal of public health, 64(6), 105-107.

Rabinow, P., \& Rose, N. (2006). Biopower today. BioSocieties, 1(2), 195-217. https://doi.org/10.1017/ S1745855206040014.

Rathee, P. (2018). What is AYUSH and the controversy around it? Deccan Herald. https://www.deccanhera ld.com/specials/what-ayush-and-controversy-703993.html 
Rezende, F., Ostermann, F., Guerra, A. (2021). South Epistemologies to invent post-pandemic science education. Cultural Studies of Science Education. https://doi.org/10.1007/s11422-021-10091-3.

Sacks, T. K. (2018). Performing Black womanhood: A qualitative study of stereotypes and the healthcare encounter. Critical Public Health, 28(1), 59-69.

Samuel, A., Chakraborty, G., \& Joy, K. J. (2020). Emerging governmentality and biopolitics of COVID-19 in India. Economic \& Political Weekly, 55(37), 27.

Sinha, B. (2020). AYUSH doctors can only prescribe drugs as immunity booster, not Covid cure, govt tells SC. The print. Retrieved from: https://theprint.in/judiciary/ayush-doctors-can-only-prescribe-drugs-asimmunity-booster-not-covid-cure-govt-tells-sc/555514/

Stoler, A. L. (1995). Race and the education of desire: Foucault's history of sexuality and the colonial order of things. Duke University Press.

Subramaniam, B. (2019). Holy science: The biopolitics of Hindu nationalism. University of Washington Press.

Sujatha, V. (2007). Pluralism in Indian medicine: Medical lore as a genre of medical knowledge. Contributions to Indian Sociology, 41(2), 169-202.

Sujatha, V., \& Abraham, L. (Eds.). (2012). Medical pluralism in contemporary India. Orient Blackswan.

TallBear, K. (2013). Native American DNA: Tribal belonging and the false promise of genetic science. U of Minnesota Press.

Žižek, S. (2020). Pandemic!: COVID-19 shakes the world. John Wiley \& Sons.

Publisher's Note Springer Nature remains neutral with regard to jurisdictional claims in published maps and institutional affiliations.

Aswathy Raveendran is a faculty member at the Homi Bhabha Centre for Science Education, Mumbai. Her areas of interest include critical studies of science education and feminist science and technology studies. She teaches courses that situate science and technology in the sociopolitical context and gender studies.

Jesse Bazzul is currently trying to find humour during the COVID-19 pandemic. His work centres on ethics and how diverse beings inhabit shared worlds. He vehemently believes that ethics lies at the heart of education, and that it's important that education be studied as one of the arts and humanities, as well as a social science and science. 